\title{
Power factor test for making and breaking experiment of mining low voltage electromagnetic starter
}

\author{
Shian Zhu ${ }^{\text {a }}$ \\ CCTEG Shenyang Research Institute, Fushun, Liaoning, 113122, China; \\ azhang651779986@126.com
}

Keywords: Mining, starter, Making and breaking, Power factor, Phase angle difference.

\begin{abstract}
Power factor is an important test condition for making and breaking capacities test of mining low voltage electromagnetic starter. Combing the reserves of coal resources with the development trend of coal industry, the structure, the application environment and the requirements of making and breaking capacities test for mining low voltage electromagnetic starter are introduced here. At the same time, we analyze the calculation method of power factor and the characteristics of direct reading method and phase angle difference method, design the making and breaking capacities test circuit used for mining low voltage electromagnetic starter, and verify the phase angle difference method used for testing power factor.
\end{abstract}

\section{Introduction}

In China's primary energy reserves, coal, petroleum and natural gas accounted for $94 \%, 1.71 \%$ and $4.29 \%$, respectively. The characteristics of energy resources in China are rich in coal, poor in oil and gas. Coal has natural dominant energy position in the development of China's economy. Since the second half of 2012, China's coal market situation has worsened due to the rapid expansion and release of coal production. However, the dominant energy position of coal cannot be shaken. According to "Coal industry development "13th Five-Year 'plan", by 2020, coal production will reach to 39 billion tons, the number of coal mines will be about 6000 , the production of large-scale coal $(\geq 1.2$ million tons) will account for more than $80 \%$, the proportion of non-fossil energy and natural gas consumption are about $15 \%$ and $10 \%$, respectively, and the proportion of coal consumption will be reduced to below $58 \%$

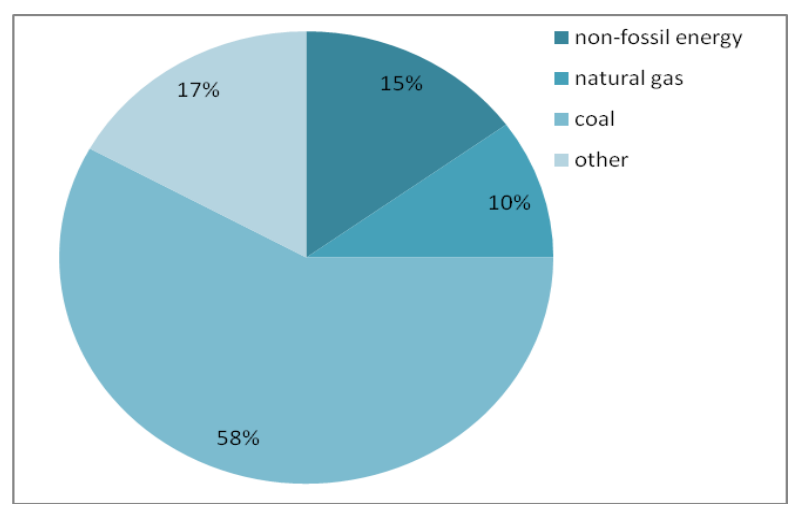

Fig.1. Planning of national energy consumption ratio by 2020

\section{Mining Low Voltage Electromagnetic Starter}

Ming low voltage electromagnetic starter (Figure 2) is mainly suitable for the underground coal mine with explosive gas mixture and coal dust. In the $50 \mathrm{~Hz}$ alternating current (AC) and 660(380)-1140 V voltage power supply system, it can be used for starting, stopping and reversing of mining flameproof three-phase squirrel cage induction motor, which can remote control the corresponding frequency and voltage. Ming low voltage electromagnetic starter is composed of flameproof enclosure and the internal AC vacuum contactor, isolating switch, control button, control 
transformer, JDB protector, fuse and overvoltage protection and other components, which has the protection functions of overload, short circuit, phase loss and leakage blocking.

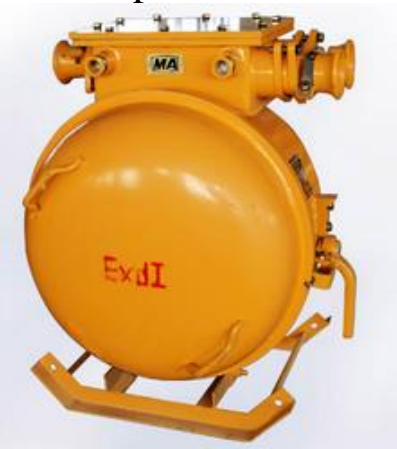

Fig.2.Mining flameproof vacuum electromagnetic starter

Mining low voltage electromagnetic starter adopts triode vacuum AC contactor and the main contact is sealed in vacuum switch tube. There is no need for maintenance and its arc is not exposed, which is suitable for frequent operation. At the same time, it has the capability of making and breaking the current required by standard. Table 1 shows the parameters of making and breaking test for mining low voltage electromagnetic starter. Herein, AC-3 means the control of starting and breaking during the running off for squirrel cage induction motor, AC-4 refers to the control of starting, inching, plug braking and reversing for squirrel cage induction motor. It can be seen from the Table 1 that the power factor of making and breaking capacity test is $0.35 \pm 0.05$.

Table 1 . The parameters of making and breaking test

\begin{tabular}{|c|c|c|c|c|c|c|c|c|c|}
\hline \multirow{2}{*}{$\begin{array}{c}\text { Utilization } \\
\text { category }\end{array}$} & \multirow{2}{*}{$\begin{array}{c}\text { Rated } \\
\text { working } \\
\text { current /A }\end{array}$} & \multicolumn{3}{|c|}{ Connection condition } & \multicolumn{3}{|c|}{ Breaking condition } & \multirow{2}{*}{$\begin{array}{c}\text { Conduction } \\
\text { time /s }\end{array}$} & \multirow{2}{*}{$\begin{array}{l}\text { Operation } \\
\text { recycling } \\
\text { times }\end{array}$} \\
\hline & & $\begin{array}{l}\text { I/ } \\
\text { Ie }\end{array}$ & $\begin{array}{l}\mathrm{U} / \\
\mathrm{Ue}\end{array}$ & $\cos \varphi \pm 0.05$ & $\begin{array}{l}\mathrm{I} / \\
\mathrm{Ie}\end{array}$ & $\begin{array}{l}\mathrm{U} / \\
\mathrm{Ue}\end{array}$ & $\begin{array}{c}\cos \varphi^{ \pm} \\
0.05\end{array}$ & & \\
\hline \multirow{2}{*}{ AC-3 } & $\mathrm{Ie} \leq 100$ & 10 & 1.1 & 0.35 & 8 & 1.1 & 0.35 & \multirow{2}{*}{0.05} & \multirow{2}{*}{50} \\
\hline & $\mathrm{Ie}>100$ & 8 & 1.1 & 0.35 & 6 & 1.1 & 0.35 & & \\
\hline \multirow{2}{*}{ AC-4 } & $\mathrm{Ie} \leq 100$ & 12 & 1.1 & 0.35 & 10 & 1.1 & 0.35 & \multirow{2}{*}{0.05} & \multirow{2}{*}{50} \\
\hline & $\mathrm{Ie}>100$ & 10 & 1.1 & 0.35 & 8 & 1.1 & 0.35 & & \\
\hline
\end{tabular}

\section{Power factor}

The current and voltage waveforms of mining low voltage electromagnetic starter are sinusoidal wave. The power factor is the cosine of the intersection angle $\varphi$ of the test power supply no-load voltage Ue and the test current Ie, which is equal to R/Z in theory.

$$
\cos \varphi=\frac{R}{Z}=\frac{R}{\sqrt{R^{2}+X^{2}}}=\frac{R}{\sqrt{R^{2}+(2 \pi \mathrm{f} L)^{2}}}
$$

In the above formula, $\mathrm{R}, \mathrm{Z}, \mathrm{X}, \mathrm{L}$ and $\mathrm{f}$ represent the total resistance, the total impedance, the total reactance, the total inductance and the power supply frequency of the test circuit, respectively.

Power factor is an important condition of making and breaking test for mining low voltage electromagnetic starter. The peak value of test current, the arc energy and the recovery voltage of transient arc extinguishing are completely different under the different power factors. The lower the power factor is, the higher the recovery voltage of transient arc extinguishing is, the greater the inductive impedance of the test line is, and the stricter the test condition is. The values and the errors of the making and breaking power factor for mining low voltage electromagnetic starter are explicitly stipulated by national coal industrial standards, as shown in Table 1. The testing methods of power factor are mainly including direct measuring and reading method, low voltage prediction method, directing current (DC) component method and phase angle difference method.

\subsection{Direct reading method}

The low voltage power factor meter, the voltage meter and the current meter are directly connected to the test circuit in the direct reading method, and the power factor can be measured directly under the 
condition of power on. The voltage signal is from the secondary side of transformer and the current signal is from the series mutual inductor in the circuit. The power factor is calculated according to the following formula:

$$
\cos \varphi=\frac{P}{I U}
$$

In the above formula, $\mathrm{P}$ is the reading of low voltage power factor meter and the unit is $\mathrm{W}$. $\mathrm{L}$ is the reading of ampere meter and the unit is $\mathrm{A}$. $\mathrm{U}$ is the reading of voltmeter and the unit is $\mathrm{V}$.

In this method, the voltage coils of voltage meter and low voltage power factor meter are connected to the low voltage side of transformer. When the current flows through the test circuit, the voltage data measured by voltage meter is the load voltage value and a little lower than the no-load voltage. The power measured by the power meter is not the active power of the full circuit, but the power consumed by the total resistance of low voltage side of the transformer, which not includes the impedance of internal resistance and power grid of transformer. Therefore, the power factor measured by the direct reading method is only the power factor of the load circuit, but not the power factor of the whole circuit.

In addition, it has the disadvantages of long conduction time and obvious heating phenomenon of the connecting wire and load impedance in main circuit. The current during the making and breaking test is large in general and the standard requires a short time, which belongs to the millisecond test operation. The connecting wire and load impedance are in short-time duty. The large testing current and severe heating phenomenon of the connecting wire and load impedance lead to the increase of test line impedance and experimental errors. Therefore, the direct reading method is not suitable for the application of circuit power factor test during the making and breaking test.

\subsection{Phase angle difference method}

Phase angle difference method is used to determine the power factor of the whole line by measuring the phase angle difference between the no-load voltage and the test current of the transformer, also known as phase relation method. The current signal is taken from the current transformer and the voltage signal is taken from the voltage transformer (the primary side of the transformer). The power factor can be obtained according to the signal phase angle difference of the voltage and current, as shown in Figure 3. At the beginning, the test current has non-periodic components and it will decay to zero after several cycles and turn to steady-state current. At the zero point $\mathrm{k}$ of steady-state current, there is $\mathrm{kj}=\mathrm{ji}=\mathrm{ih}=\mathrm{hg}=\mathrm{gf}=\mathrm{fe}=\mathrm{ed}=\mathrm{dc}$, in which the length of $\mathrm{kj}$ is the half wave length of steady-state current and the corresponding angle is $\pi$. Extending the length, point $\mathrm{c}$ can be obtained, and the point $b$ is acquired by zero point a of no-load voltage. Then the power factor of test circuit is calculated according to the length of the bc. The advantage of this method is that the power factor of the circuit can be measured in a large range, and the disadvantage is that the influence of the power grid impedance is not included. Hence, it is not the whole circuit power factor. However, if the short-circuit capacity of the power grid is 10 times higher than that of the test capacity, the effect can be ignored. The power factor of making and breaking test of mining low voltage electromagnetic starter is about $0.35 \pm 0.05$ and the test current is $2000 \mathrm{~A}$. The ratio of short circuit capacity of the power grid to the test capacity is greater than 10. Consequently, the phase angle difference method is suitable for measuring power factor of making and breaking test for mining low voltage electromagnetic starter. 


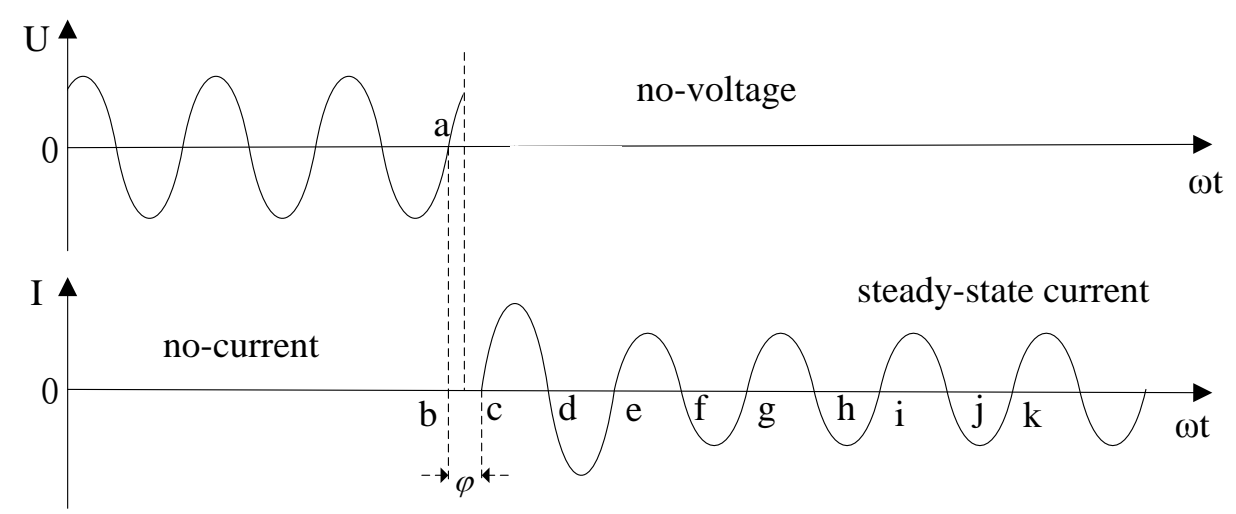

Fig. 3 The schematic of using phase angle difference to measuring power factor

\section{Power Factor Test}

The circuit of making and breaking test for mining low voltage electromagnetic starter is mainly composed of power supply, pre-impedance, sample, back stage impedance and grounding devices. Figure 4 is the making and breaking test circuit diagram of coal isolating change-over switch, where $S$ is the power supply, R1 and L1 are pre-impedances, R2 and L2 are back stage impedance, GM is the sample, $\mathrm{O} 2$ is the voltage measuring port, $\mathrm{O} 3$ is the current transformer, $\mathrm{M}$ is temporary connection used for tuning and $\mathrm{G}$ is the earth point. There will be large fault current due to the occurrence of inter-phase short circuit during the test. Hence, in order to limit the fault current, it is allowable to connect certain pre-impedance between the tested contactors of apparatus and the power supply. The sum values of the pre-impedance and the internal resistance of power supply are no more than 0.1 times of the total impedance of the experimental circuit.

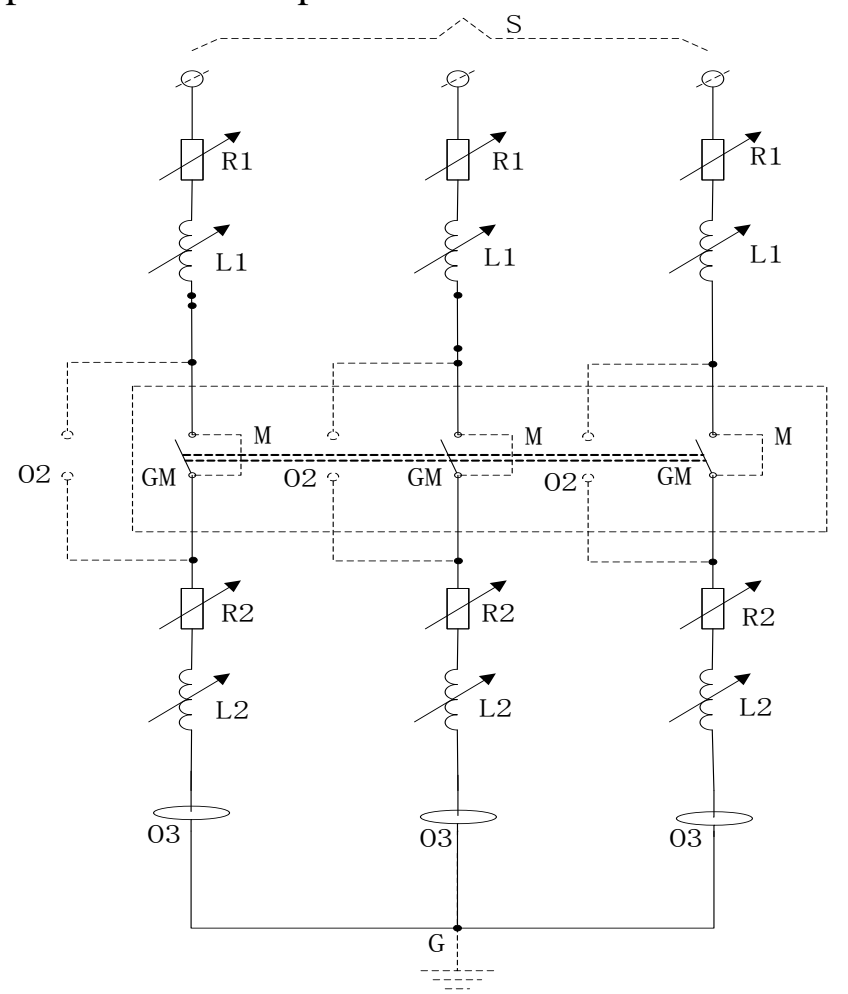

Fig. 4 The circuit diagram of making and breaking capacity test for mining low voltage electromagnetic starter

The connection test of the mining low voltage electromagnetic starter with the rated current $200 \mathrm{~A}$ is used as an example to verify the phase angle difference method. According to the provisions of the standard, the test current is 10 times higher than the rated current and the power factor in test circuit is 0.35 . The withstand voltage should be verified after testing. The data of connection test for mining 
voltage electromagnetic starter is collected by acquisition system, as shown in Figure 5. It can be seen that the test voltage is $1260 \mathrm{~V}$, the power factor is 0.39 (According to the time difference between the no-load voltages and test current is $3.7 \mathrm{~ms}$, calculate the angle difference $\left(67^{\circ}\right)$ to obtain power factor) and the test current is $2000 \mathrm{~A}$. The experiment results show that the phase angle difference method can be used to test the power factor of the mining low voltage electromagnetic starter and meet the demands of product inspection.

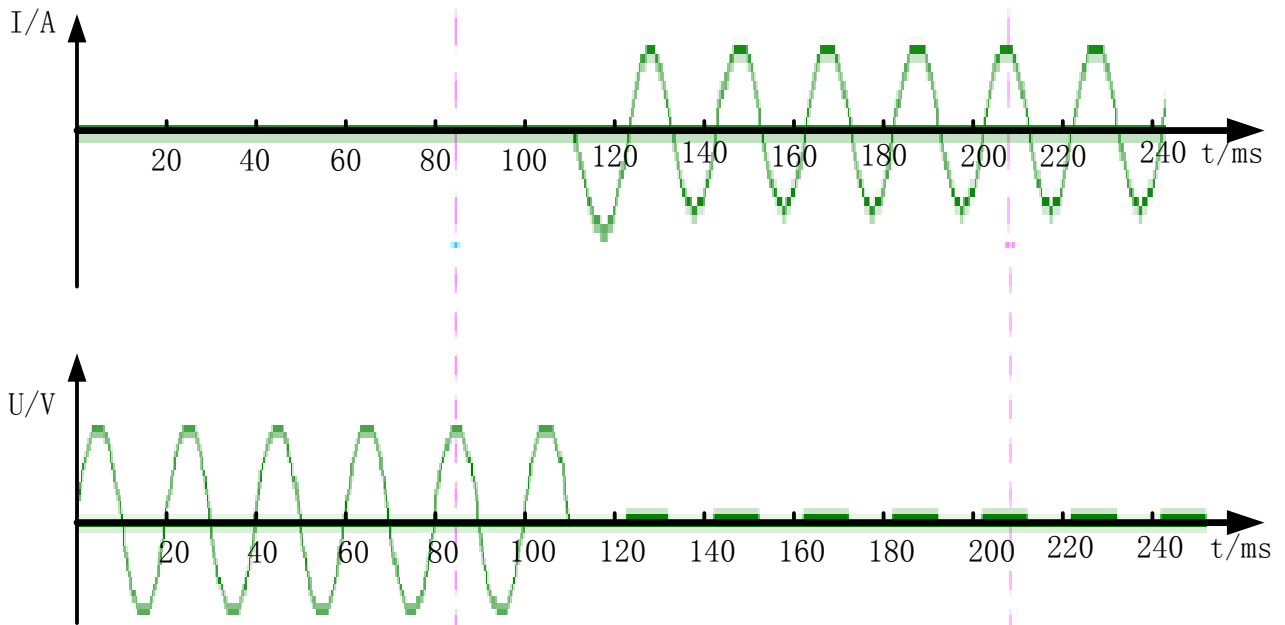

Fig. 5 The connection diagram of mining low voltage electromagnetic starter

\section{Conclusion}

Mining low voltage electromagnetic starter is the important electrical equipment of underground coal mine, and it is used for controlling and protecting the motor starting, running and stopping. The making and breaking capacity test is an important test item for project setting test. On the basis of analyzing the requirements in the national standard, the direct reading method and phase angle difference method used for testing power factor are compared. The experiments show that the phase angle difference method is suitable for making and breaking capacity test of mining low voltage electromagnetic starter. The research results have certain guiding significance for mining electric equipment products test.

\section{References}

[1]. YAN Qun. Design and analysis of insulation structure of solid insulation switchgear. Mechanical Research \& Application, No.5, 77-80, 2009.

[2]. HAN She-jiao, MA Xi-kui, GUO Guo-ling. Electrical fields' computation of tank type metal-oxide surge arrester for 110kV GIS. Insulators and Surge Arresters, No.1, 33-35, 2002.

[3]. DANG Zhen-ping, PEN Zong-ren. Errosion test on 500kV composite rod insulator fractured in service and its electric tress estimation. Insulators and Surge Arresters, No.4, 1-7, 2005.

[4]. GAO Bo, ZHANG Ya-ting, WANG Qing-liang, et al. Effect of pollution non-uniformity on electric field of contaminated insulator. Insulators and Surge Arresters, No3, 13-16, 2008.

[5]. WEN Kang-zhen, WEN Yuan-fang, DUANMU Lin-nan, et al. The error of ANSYS solution of electrostatic field produced by sharp electrode. Insulators and Surge Arresters, No.2, 14-16, 2009.

[6]. LU Ming, YANG Qing, YAN Dong, et al. The effect of the composite snsulators sheds type structure on the electric field distributions. Insulators and Surge Arresters, vol.1, 1-6, 2011. 